\title{
El pacto fiscal, único camino para salir de la crisis financiera del gobierno
}

\author{
Lic. Mauricio Aguiluz \\ Economista, Consultor y Docente Universitario
}

\section{Resumen}

Este artículo hace una reflexión respecto a la crisis financiera del gobierno salvadoreño, provocada por el excesivo endeudamiento público, la débil recaudación tributaria, y la irracionalidad en el gasto público, el contraer deudas para pagar deudas, sobre el envío de un mensaje claro a la población de que los escasos recursos del gobierno se quieren utilizar de manera eficiente y con total austeridad, que la crisis fiscal no es un problema que afecta en forma aislada al gobierno, sino que tiene un impacto que incide en todo el país, tanto en lo económico como en lo social; y que se debe tener claridad de que este problema no es responsabilidad solo del actual gobierno, sino que es el resultado acumulado de las decisiones que se han tomado en los últimos 25 años; además de presentar propuestas para aprovechar el momento para convertir la crisis en oportunidad, para corregir las decisiones que no han dado buenos resultados, sino que al contrario están contribuyendo a profundizar los problemas.

\section{Palabras clave}

Crisis económica, endeudamiento público, política fiscal, El Salvador.

Estamos en un período pre-electoral, donde ya se definieron los tres principales contendientes para ocupar la silla presidencial y las elecciones son a principios del 2014, situación que en mi opinión nos ubica en el momento más oportuno para discutir y plantear alternativas de solución a la grave crisis financiera del gobierno, la cual se explica en tres grandes componentes: 1) excesivo endeudamiento público, 2) débil recaudación tributaria y 3) la irracionalidad en el gasto público.

\begin{abstract}
This article is to think about the Salvadoran government's financial crisis, caused by excessive public debt, weak tax collection, and irrationality in public spending, contracting debts to pay debts, about sending to the population a clear message that scarce government resources are to be used efficiently and with complete austerity, the fiscal crisis is a problem that affects the government alone, but has a striking impact across the country, both economically and socially, and that should be clear that this problem is not only the responsibility of the current government, but is the cumulative result of the decisions that have been taken in the last 25 years, in addition to presenting proposals to develop the time to turn crisis into opportunity, to correct the decisions have not been successful, but instead are helping to deepen the problems.
\end{abstract}

\section{Keywords}

Economic crisis, public debt, fiscal policy, El Salvador.
La deuda pública ronda el $54 \%$ del producto interno ${ }^{1}$, bruto, indicador que no parece muy elevado si solo vemos la capacidad de endeudamiento del país, pero si vemos la capacidad de pago; es decir, cuánto de los ingresos corrientes necesitamos para hacer frente al servicio de la deuda, nos damos cuenta que se requiere alrededor del $40 \%$, lo cual si es preocupante, ya que deja sin recursos al gobierno para atender las necesidades del país, lo que obliga a entrar al

1 Fuente: Banco Central de Reserva 
"circulo vicioso" de contraer más deudas para pagar la deuda y esto lleva al gobierno al precipicio y ningún gobierno puede solucionarlo solo.

Con relación al gasto público, en primer lugar, se debe enviar un mensaje claro a la población de que los escasos recursos del gobierno se quieren utilizar en forma eficiente y con total austeridad; es decir, eliminando todos los gastos innecesarios, así para el caso de la Asamblea Legislativa, según datos del Ministerio de Hacienda en su página web, en el año 2002 se le asignaron \$16.7 millones y tenía 391 empleados, incluyendo a los Diputados, mientras que en el año 2012 se le asignaron \$56.3 millones y tenían 1531 empleados, lo cual significa un incremento del $237 \%$ de los recursos asignados y del $292 \%$ de los empleados, mientras la población no percibe ningún beneficio de ello y lo mismo ocurre en el Órgano Judicial, donde en el año 2002 se le asignaron $\$ 112.9$ millones y tenían 5,866 empleados, mientras que en el año 2012 se le asignaron $\$ 226.9$ millones y tenían 9,957 empleados, o sea casi diez mil, lo que representa un incremento de más del 100\% en recursos y en empleados y de igual forma la población no percibe ningún beneficio y la mora en los procesos judiciales continúa igual y lo peor es que los empleados, a pesar de que son los mejor pagados en todo el sector público, exigen y reciben bonos navideño de $\$ 1,000.00$, lo que significa $\$ 10,000,000.00$ adicionales en un solo plumazo, además de otras prestaciones, y de igual forma ocurre en Casa Presidencial, la Corte de Cuentas de la República y otras instituciones del Estado.

Se debe tomar conciencia de que la crisis fiscal no es un problema que afecta en forma aislada al gobierno, sino que tiene un impacto que incide en todo el país, tanto en lo económico como en lo social; también se debe tener claridad de que este problema no es responsabilidad solo del actual gobierno, sino que es el resultado acumulado de las decisiones que se han tomado en los últimos 25 años, así por ejemplo en el caso de la deuda al inicio del gobierno del Lic. Cristiani el saldo era de $\$ 2,105.1$ millones $^{2}$, mientras que a diciembre de 2012 llegó a $\$ 14,493.1$ millones $^{3}$ y por lo mismo, la solución requiere del concurso y del compromiso de todos, poniendo los intereses del país por encima de los intereses ideológicos de los partidos políticos, de las gremiales empresariales y de los demás sectores, procurando si, que el costo de la solución no caiga en los hombros de las familias más pobres del país.

\footnotetext{
Fuente: Periódico Expansión 04-2012

Ministerio de Hacienda y BCR.
}

Si se actúa con valentía y pensando en el país que queremos dejar a nuestros hijos y nietos, se puede aprovechar el momento para convertir la crisis en una gran oportunidad para corregir las decisiones que no han dado buenos resultados, sino que al contrario están contribuyendo a profundizar los problemas y para ello se propone lo siguiente.

1. Suscribir un Pacto Fiscal por lo menos entre los tres principales partidos políticos, la empresa privada y el gobierno, en el cual se definan las políticas de ingresos y gastos del gobierno, para el corto, mediano y largo plazo, con el objetivo de superar la crisis fiscal y de endeudamiento público e impulsar el crecimiento de la economía del país.

Un pacto fiscal es un acuerdo político entre los distintos sectores sociales, mediante el cual, parte de la Agenda Pública es convertida en programas y políticas de Estado y el acuerdo también debe determinar la cuantía de los recursos públicos requeridos, su origen y las reglas para su asignación y ejecución.

El Pacto Fiscal es un compromiso de largo plazo que busca fundamentar el proceso de un enfoque integral de las finanzas públicas con base en:

- Consensuar una visión nacional sobre el país que se desea

- Establecer metas concretas y realistas para desarrollar el país en base a la visión que tenemos

- Acordar la estrategia para alcanzar las metas

- Determinar la forma de obtener los recursos necesarios para cumplir las metas establecidas

- Asegurar la optimización del uso de los recursos públicos.

2. Dentro de las medidas a tomar se sugiere por el lado de los ingresos, establecer el Impuesto Predial, tomando en cuenta que El Salvador es el único país de América que no lo tiene y dejar establecido en la Ley que los recursos provenientes del mismo, sean utilizados por los municipios exclusivamente para proyectos de inversión pública en desarrollo local, para impulsar el crecimiento económico del país.

3. Por el lado del gasto, se sugiere modificar la Constitución para eliminar el $6 \%$ de los ingresos corrientes del presupuesto que se asigna al Organo Judicial y que sea el Ministerio de Hacienda quien le asigne los recursos de acuerdo a sus necesidades y a la disponibilidad de recursos del Gobierno.

4. Modificar la Constitución para eliminar la facultad que tiene el Organo Legislativo de asignarse su propio presupuesto, 
debido a que han abusado de esta situación y que sea el Ministerio de Hacienda quien les asigne los recursos de acuerdo a sus necesidades y a las disponibilidades de recursos del gobierno.

5. Reducir el número de Diputados de 84 a 42, tomando en cuenta que las decisiones las toman dos o tres miembros de cada partido y los demás solo llegan a levantar la mano y además, dejar establecido que los suplentes solo tendrán salario cuando sustituyan al propietario, porque en la práctica actualmente tenemos 168 diputados, debido a que los Suplentes reciben un salario mensual.

6. No deben haber empleados públicos de primera y segunda categoría, por lo que deben eliminarse todo tipo de bonos y seguros de vida y de salud privados, ya que esto genera distorsiones e inequidades entre los servidores públicos.

7. Reducir al mínimo los viajes al exterior, así como el número de participantes y prohibir los vuelos en clase ejecutiva, para servidores públicos.
8. De acuerdo a datos de la Dirección de Educación Superior del Ministerio de Educación, actualmente se gradúan cada año, unos 18 mil profesionales en las universidades del país, la mayoría de los cuales no encuentran trabajo o están subempleados en call center o en ventas, mientras cerca de diez mil empleados públicos jubilados, continúan en el mismo trabajo, recibiendo un doble sueldo, impidiendo que jóvenes con nuevos conocimientos y deseos de superación ingresen al sector, por lo que se debe reformar la Ley del Sistema de Ahorro para Pensiones emitida en 1996, mediante D.L. 927 para dejar establecido que "la pensión es incompatible con un trabajo remunerado en el sector público" y emitir un Decreto Legislativo que deje sin efecto los contratos de las personas jubiladas que continúan trabajando en el sector público, para dar oportunidad a estos nuevos profesionales.

9. Los subsidios deben continuar y en el caso del gas licuado, debe focalizarse más pasando de 199 kvh de consumo a 100 kvh, para que llegue solo a las familias más pobres y no deben financiarse con endeudamiento público. 